\title{
EDITORIAL
}

\section{Analysing Human-Nature Interactions: allowing for Multiple Agents and Power Structures}

\author{
Kanchan Chopra *
}

In the second issue of the Journal, we address a range of issues and methodological approaches, continuing with the perspective of a transdisciplinary, pluralistic approach to interactions between society and nature. We begin with a focus on environmental issues (other than climate change) that have captured media attention in the recent past. Given our vantage point of South Asia, so-called 'local' issues such as air pollution and water governance as well as issues related to urban conglomerations seem to be in the forefront.

In the 'Conversations' section, experts reflect on different approaches to the first two, air and water. How did academics of different persuasions seek policy solutions to these? We were proffered a range of solutions for air pollution, ranging from those based on technology to those involving paradigm changes in models of development and convergence between different governing entities. In the case of water, the call is again for integration of ecological perspectives into water governance and for a reshaping of the ossified structures of governance at both the national and global level. Better convergence among science, policy, and governance structures is called for to tackle effectively these pressing local issues.

Urban conglomerations and the manner of their evolution is the topic of a thematic essay as well as of one of the Notes from the Field'. These contributions highlight the lack of convergence between social and ecological imperatives. In the spirit of 'political ecology', these contributions seek to analyse and throw light on, rather than guide, policy. The picture

\footnotetext{
* Coordinating Editor (2017-18). Former Director and Professor, Institute of Economic Growth, University Enclave, North Campus, Delhi 110007; choprakanchan14@gmail.com.

Copyright (C) Chopra 2018. Released under Creative Commons Attribution-NonCommercial 4.0 International licence (CC BY-NC 4.0) by the author.

Published by Indian Society for Ecological Economics (INSEE), c/o Institute of Economic Growth, University Enclave, North Campus, Delhi 110007.
}

ISSN: 2581-6152 (print); 2581-6101 (web).

DOI: https://doi.org/10.37773/ees.v1i2.30 
that emerges is one of changing landscapes in a scenario driven by power, both political and economic. And a course correction would need to address these levers of change.

The 'commentary' and 'research papers' sections elucidate methodological issues in the context of future and present research. Perrings and Kinzig investigate the link between biological conservation and economic theory, illustrating how early formulations of the conservation problem in economic theory deepened the understanding of the aims and objectives of conservation biology. In his commentary, Liu holds that a 'metacoupling' between human and natural factors (with due understanding of 'agents, causes, and effects') both locally and across space holds the key to progress in understanding economy-human relationships. It will also enable the achieving of the Sustainable Development Goals (SDGs) of the United Nations by clarifying the nature of association between ecosystems and people — both those adjacent and those far removed in space.

Interestingly, the research paper included in this issue also examines interrelationships between an ecosystem and the people living within it, using scenario analysis with a system dynamics approach. The rapid growth of an invasive species in an ecosystem alters its dynamics; and the paper examines how alternative policy scenarios, such as removal of the invasive species, impact it. Another evocative contribution comes from critical analysis of the deliberations of two conferences, both presenting a spectrum of issues and concerns.

In sum, this issue of Ecology, Economy and Society-the Joumal of INSEE presents alternative ways of looking at the human-nature link. Some contributions introduce unequal distribution of power and wealth and outdated governance structures into the picture. It is a heady mix, which we hope will encourage further analytical thinking and research on these issues - across different kinds of ecosystems, located within diverse political and social systems. 